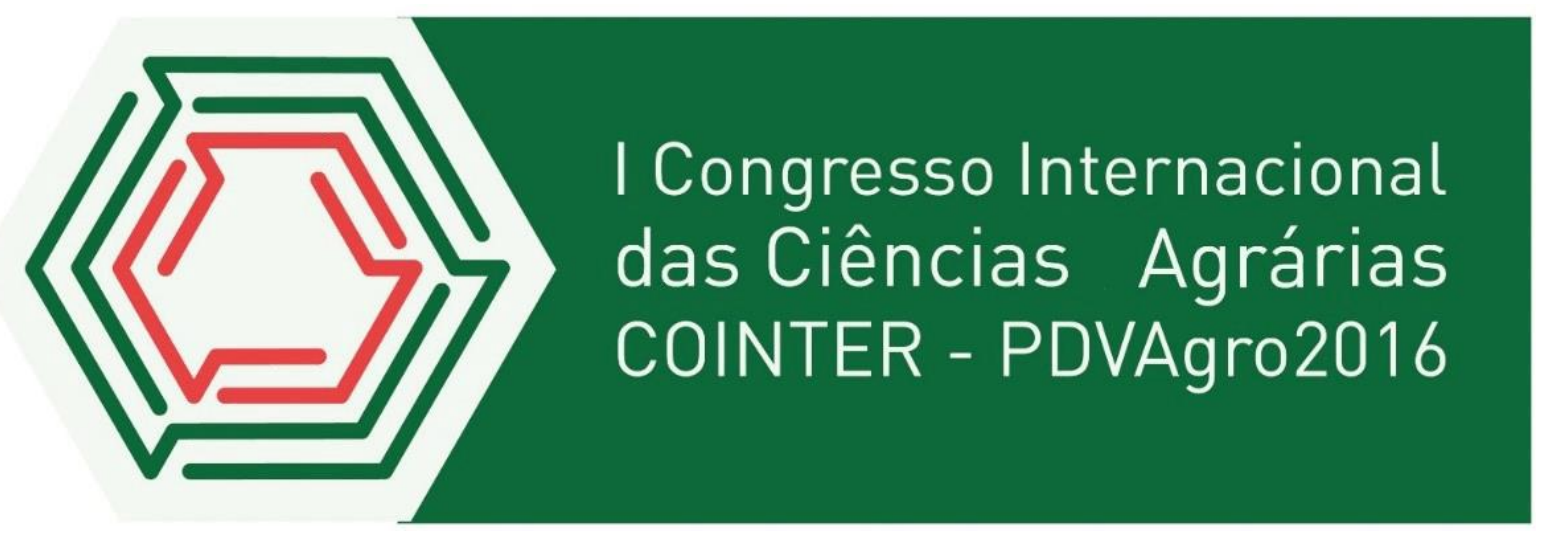

\title{
IDENTIFICANDO BENCHMARKS NA PRODUÇÃO DE LEITE NO AGRESTE PERNAMBUCANO
}

\author{
Apresentação: Comunicação Oral \\ Josefa Edileide Santos Ramos ${ }^{1}$; Marcelo da Costa Borba ${ }^{2}$; Maria do Carmo maracajá Alves ${ }^{3}$ \\ Daniela Moreira de Carvalho ${ }^{4}$ Rodolfo Araújo de Morais Filho ${ }^{5}$
}

\section{Resumo}

Este trabalho teve por objetivo selecionar indicadores de resultados e determinar benchmark de indicadores em sistemas de produção de leite no agreste pernambucano. Analisaram-se os indicadores zootécnicos, econômicos e de tamanho das propriedades. Foram selecionadas três fazendas para servir de orientação para as demais, como critério de escolha considerou-se aqueles que alcançaram os melhores resultados em alguns indicadores globais dos quais as respectivas propriedades se destacaram. As propriedades selecionadas foram denominadas segundo o estrato de produção, a produtividade média por vaca em lactação e as implicações econômicos das propriedades. Os resultados para fatores de intensificação do uso da terra (vacas em lactação e produção de leite por hectare) foram 0,5 animal/ha e média de 4,8 L/ha/dia para Fazenda A, de 0,99 animal/ha e 10,2 L/ha/dia Fazenda B e 0,65 animal/ha e 12 $\mathrm{L} /$ ha/dia para a fazenda C. Foram analisados os gastos com concentrado para o rebanho em relação à renda bruta, gasto com mão-de-obra em relação à renda bruta e participação do custo operacional efetivo na renda bruta da atividade. A fazenda A apresentou $24 \%, 3,5 \%$ e $67,6 \%$, respectivamente, a Fazenda B $27,8 \%, 13,9 \%$ e $66,1 \%$ e por último a fazenda C 38,8 $\%, 31,7 \%$ e $66,48 \%$. Os indicadores de Benchmark resultantes para a medição de desempenho mostraram-se muito eficaz. De forma a verificar a viabilidade operacional e econômica da atividade de produção leiteira no agreste pernambucano. Fornecendo acurácia de informações indispensáveis para o planejamento e tomada de decisão dos produtores rurais em vista do desenvolvimento do setor leiteiro na microrregião de Garanhuns.

Palavras-Chave: Atividade leiteira. Custos de produção. Indicadores de desempenho.

\section{Introdução}

No setor primário nacional, a pecuária leiteira tem grande expressão face ao potencial de geração de receitas e investimentos, sendo também bastante expressiva a demanda de bens

\footnotetext{
${ }^{1}$ Pós-Graduação em Administração e Desenvolvimento Rural, UFRPE, edileideramos@ gmail.com

${ }^{2}$ Pós-Graduação em Administração e Desenvolvimento Rural, UFRPE, marcelodcborba@gmail.com

${ }^{3}$ Pós-Graduação em Administração e Desenvolvimento Rural, UFRPE, alvesmariacm@gmail.com

${ }^{4}$ Doutora em Agronegócio, UFRPE, dmc@uag.ufrpe.br

${ }^{5}$ Doutorado em Administração, UFRPE, rodolfoamfilho@yahoo.com.br
} 
e serviços. Diante desta realidade, o produtor rural deve buscar novas tecnologias e priorizar a atualização de informações, adotando mecanismos de aprendizagem e formação profissional, transformando as propriedades em empresas capazes de acompanhar a evolução do setor.

Neste sentido, o mercado cada vez mais competitivo, exige um planejamento de seus custos e receitas que lhe permitam gerir seu negócio com segurança. Desta forma, a mensuração dos custos de produção torna-se um subsidio no processo decisório, agindo com eficácia nas decisões. Assim o desenvolvimento de um sistema gerencial de planejamento e custos agropecuários é uma ferramenta essencial para o gerenciamento das unidades produtora.

Os produtores de leite de elevada eficiência econômica podem se tornar ponto referência ou Benchmarks para os demais. A comparação entre os resultados do produtor com os de seus vizinhos pode leva-lo a desafios e contribuir para aumentar sua eficiência. Uma das principais fontes de inovação tecnológica, na produção de leite, é o outro produtor(GOMES, 2005), o capital humano é determinante no processo. Entretanto, a grande diversidade nos sistemas de produção de leite brasileiro devido aos fatores socioeconômicos, tecnológicos, culturais e edafoclimáticas que afetam a produção, impõem a necessidade de fazer estudos periódicos conforme a realidade de cada região(OLIVEIRA et al., 2007).

Este trabalho tem como objetivo selecionar indicadores de resultados e determinar Benchmark, em sistemas de produção de leite no agretse Pernambucano. A seleção desses indicadores e a determinação de Benchmarks representam orientação segura para o produtor visto que os valores apresentados foram obtidos de outros produtores que vivem no mesmo ambiente econômico, e passam pelas mesmas dificuldades(GOMES, 2005).

\section{Fundamentação Teórica}

O potencial de produção existente e o mercado de lácteos em plena expansão são fatores que evidenciam as boas oportunidades de negócios envolvendo a pecuária de leite. A importância no desempenho econômico e na geração de emprego no país é incontestável, visto que a produção de leite está entre as principais atividades do setor agropecuário, presente em cerca de 1,3 milhões de propriedades brasileiras, responsável pela geração de bilhões de reais anuais e de milhares de empregos no meio rural (REIS FILHO; SILVA, 2013).

A produção de leite de vaca no Brasil cresceu a uma taxa relativamente constante desde 1991. O país saiu do patamar de 15,1 bilhões de litros de leite produzidos naquele ano, alcançando o de 35,17 bilhões de litros em 2014 (IBGE, 2014). Isto devido às mudanças 
econômicas ocorridas desde a década de 1990. Essas mudanças estão associadas, principalmente, aos impactos da estabilização da economia em decorrência do Plano Real, desregulamentação do mercado e abertura econômica que exigem ajustamentos estratégicos e estruturais do setor (JANK; FARINA; GALAN, 1999).

Em 2014, o Sul assumiu a primeira posição no ranking, com 34,7\% da produção nacional. A produção leiteira nacional é bastante concentrada nessas regiões. Os seis principais estados produtores (Minas Gerais, Rio Grande do Sul, Paraná, Goiás, Santa Catarina e São Paulo) correspondem a 76,8\% da produção total do país. E ainda, adicionando o volume produzido pela Bahia tem-se a participação $(80,3 \%)$ desses sete estados na produção nacional.

No Nordeste, as concentrações da produção de leite estão no Sertão e no Agreste, a exemplo das mesorregiões dos sertões cearenses, alagoano, paraibano, sergipano, agreste pernambucano e central potiguar, já que o clima se torna mais adequado para a criação do gado. No período de 2000 a 2010 apresentou um crescimento de 95,5 \% maior que a média nacional que foi de $55,4 \%$, isso aconteceu devido ao aumento da produção de leite nos estados de Pernambuco, Maranhão, Sergipe e Paraíba (REIS FILHO; SILVA, 2013).

De acordo com a pesquisa pecuária municipal (IBGE, 2013) a região nordeste representa $10,5 \%$ da produção nacional de leite, estando atrás do Sudeste com $35,1 \%$, Sul $34,4 \%$ e Centro-Oeste 14,6\%. Dentre os estados nordestinos, a Bahia é o maior produtor de leite, representando $29,9 \%$ da produção regional. Porém esta participação vem diminuindo nas duas últimas décadas. Pernambuco ocupa a segunda posição com 15,6\% na produção leite na região nordeste.

A cadeia do leite é a principal atividade para dezenas de municípios do sertão e, principalmente do Agreste do Pernambuco onde está concentrada a bacia leiteira do estado. A mesorregião representa 75,5\% da produção do estado (IBGE, 2014). No entanto, a cadeia produtiva do leite apresenta grandes dificuldades técnicas e administrativas, o baixo nível tecnológico aplicado na exploração leiteira e a falta de gestão mais profissionalizada nas propriedades conferem ao segmento produtivo indicadores técnicos aquém das suas reais potencialidades.

Uma das estratégias que os produtores de leite dispõem para tornar seu produto competitivo é a redução dos custos de produção, cujo conhecimento é essencial para o efetivo controle da empresa rural (FASSIO et al., 2005). O custo de produção é um instrumento necessário para administrar a atividade leiteira, pois é através dessa análise que o produtor 
passa a utilizar corretamente os fatores de produção, detectando pontos de estrangulamento e facilitando o processo decisório (LOPES; CARVALHO, 2000).

$\mathrm{Na}$ atividade leiteira o que interessa é o todo, custo em conjunto com o preço e renda, o que determinará o lucro da atividade em questão. Onde os espaços de tempo entre custos e receitas, fogem à simplicidade de outros tipos de negócio. Exigindo técnicas especiais para apresentação não dos custos, mas dos resultados econômicos do empreendimento(MARION; SANTOS; SONIA, 2009).

Dentre os fatores que podem influenciar o custo de produção estão a produtividade e nível tecnológico do sistema de produção de leite. É preciso coordenar os fatores de produção de acordo com determinada tecnologia. Em que o objetivo é alcançar um certo nível de produção que proporcione a máxima eficiência econômica, ou seja, maximizar o lucro ou minimizar os custos (LOPES et al., 2007). A tecnologia é capaz de promover o aumento da produtividade e a redução no custo de produção.

A eficiência como medida de desempenho fornece elementos que podem ampliar o poder de tomada de decisão. Inserido neste contexto o Benchmarking, é um instrumento valioso para os produtores de leite, pois ao identificar os sistemas de produção eficientes (Benchmarks), estarão sendo identificadas as melhores práticas produtivas para as unidades ineficientes, facilitando também o trabalho da pesquisa e da extensão rural (TUPY; YAMAGUCHI, 2002).

Estudos têm sido realizados visando avaliar a eficiência dos produtores e identificar os principais indicadores zootécnicos e econômicos que influenciam a rentabilidade dos sistemas de produção de leite. Na literatura destacam-se os trabalhos de Krug (2001) Gomes (2005), Menegaz et al. (2006), Oliveira et al. (2007) e Camilo Neto et al. (2012). Algumas pesquisas de trabalhos já publicados sobre o tema podem ser observados no quadro 1.

Quadro 1: Estudos sobre benchmarks na pecuária Leiteira. Fonte: Elaborado pelo autor (2015).

\begin{tabular}{|c|c|c|c|}
\hline Autores & Objetivos & Metodologia & Principais resultados \\
\hline $\begin{array}{l}\text { Gomes } \\
(2005)\end{array}$ & $\begin{array}{l}\text { Selecionar indicadores de } \\
\text { resultados e determinar } \\
\text { Benchmark na produção de } \\
\text { leite de Minas Gerais. }\end{array}$ & $\begin{array}{l}\text { Foram selecionados } 5 \\
\text { indicadores para os } \\
\text { produtores de do estado de } \\
\text { Minas Gerais, foram } \\
\text { selecionados } 27(10 \% \text { de } 272) \\
\text { dos que alcançaram os } \\
\text { melhores resultados em cada } \\
\text { um dos indicadores. }\end{array}$ & 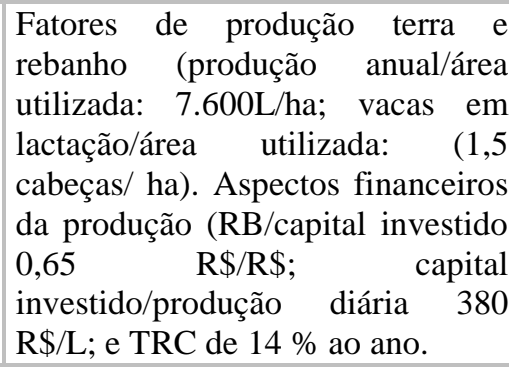 \\
\hline $\begin{array}{c}\text { Menegaz, et } \\
\text { al (2006) }\end{array}$ & $\begin{array}{l}\text { Avaliar a evolução dos } \\
\text { coeficientes de desempenho } \\
\text { técnico e econômico das UPs } \\
\text { benchmark que participaram } \\
\text { dos três períodos de análise } \\
\text { do Sistema Benchmarking. }\end{array}$ & $\begin{array}{l}\text { Pesquisa descritiva e } \\
\text { exploratório. Foram avaliadas } \\
\text { as UPs que participaram das } \\
\text { três fases de análise do } \\
\text { Sistema Benchmarking. }\end{array}$ & $\begin{array}{l}\text { Auxílio aos produtores benchmark } \\
\text { a medir o grau de eficiência da } \\
\text { atividade e detectar os pontos } \\
\text { fracos do sistema produtivo. } \\
\text { Destaque para o Condomínio Rural } \\
\text { Cristal. }\end{array}$ \\
\hline
\end{tabular}




\begin{tabular}{|c|c|c|c|}
\hline $\begin{array}{l}\text { Oliveira, et } \\
\text { al (2007) }\end{array}$ & $\begin{array}{l}\text { Identificar e quantificar } \\
\text { indicadores-referência de } \\
\text { sistemas de produção de leite } \\
\text { no Extremo Sul da Bahia. }\end{array}$ & $\begin{array}{l}\text { Método de custo operacional } \\
\text { de produção. Analisados os } \\
\text { indicadores de resultados, } \\
\text { identificando os que afetam o } \\
\text { desempenho econômico das } \\
\text { empresas. Equações de } \\
\text { regressão para quantificar os } \\
\text { indicadores-referência. }\end{array}$ & $\begin{array}{l}\text { A pecuária leiteira é uma atividade } \\
\text { rentável mesmo em sistemas } \\
\text { menos intensivos na utilização dos } \\
\text { recursos produtivos terra, mão-de- } \\
\text { obra e animais, porém exige } \\
\text { elevada disponibilidade de terra, o } \\
\text { que pode limitar sua adoção em } \\
\text { larga escala. }\end{array}$ \\
\hline $\begin{array}{l}\text { Neto, et al } \\
\text { (2012) }\end{array}$ & \begin{tabular}{llll} 
Identificar & e & \multicolumn{2}{c}{ quantificar } \\
benchmarks & de & sistema & de \\
produção de & leite & no \\
Triângulo Mineiro. &
\end{tabular} & $\begin{array}{l}\text { Foram analisados indicadores } \\
\text { zootécnicos e econômicos e } \\
\text { de tamanho das empresas } \\
\text { rurais. Os valores de cada } \\
\text { indicador foram estimados, } \\
\text { considerando quatro cenários } \\
\text { de taxa real de remuneração } \\
\text { do capital investido. }\end{array}$ & $\begin{array}{l}\text { Os fatores produtividade da terra e } \\
\text { rebanho apresentam maior } \\
\text { correlação com a lucratividade do } \\
\text { que os fatores associados à } \\
\text { produtividade do trabalho, } \\
\text { independentemente do tamanho da } \\
\text { produção. Benchmarks obtidos } \\
\text { para o Estado de Minas Gerais } \\
\text { diferem dos índices globais. }\end{array}$ \\
\hline
\end{tabular}

De acordo com os autores os principais indicadores que influenciam na rentabilidade do sistema de produção estão relacionados os fatores de produção terra e rebanho. Eles englobam medidas de eficiência reprodutiva com as de uso da terra. A divulgação das informações obtidas através da identificação benchmark tem auxiliado o setor produtivo como um todo a se profissionalizar na atividade leiteira. Porém os sistemas de produção são complexos e diferem entre si o que indica a necessidade de estudos regionalizados.

A identificação de sistemas reais de produção de leite e a caracterização dos indicadores de maior correlação com a eficiência econômica poderão trazer maior embasamento para o debate sobre a viabilidade econômica na pecuária leiteira (OLIVEIRA et al, 2007). Ao identificar Benchmarks, as técnicas de medição de eficiência podem facilitar o intercâmbio de informações tecnológicas e de gestão o que favorece a definição de estratégias mais aplicadas.

\section{Metodologia}

Para alcançar os objetivos fixados nesta pesquisa foram avaliadas vinte propriedades produtoras de leite, localizadas no agreste pernambucano, microrregião de Garanhuns. Sendo 9 propriedades alocadas no município de Garanhuns e 11 em São Bento do Una. A partir de uma análise sucinta do universo amostral (20 propriedades), foi utilizada uma amostra não probabilística definida pelo critério de intencionalidade, a amostra foi composta por três propriedades que apresentaram os melhores resultados. Esta amostra foi selecionada da seguinte forma: através de uma análise comparativa dentre os indicadores econômico das fazendas com a finalidade de encontrar a maior eficiência relativa da amostra.

Os dados originaram-se de registros mensais, realizados durante 6 meses, coletados entre novembro de 2014 a abril de 2015. O tratamento dos dados foi feito pelo método 
quantitativo, onde foram analisados indicadores zootécnicos, econômicos e de tamanho, de todas as unidades produtoras. Os indicadores de tamanho analisados foram: produção diária de leite (litros); área total (ha); número de vacas em lactação (unidade animal), total de vacas (unidade animal), total do rebanho (unidade animal).

Os indicadores zootécnicos foram: produtividade por vaca em lactação (litros/vaca/dia); relação de vacas em lactação pelo total de vacas (\%); relação de vacas em lactação pelo total do rebanho (\%); número de vacas em lactação por área (vacas/ha) e produtividade da terra (litros/ha/dia). Os indicadores econômicos analisados foram: renda bruta da atividade leiteira-RB; custo operacional efetivo da atividade leiteira COE; gasto com concentrado para o rebanho em relação ao valor da produção de leite e gasto com mão-deobra contratada em relação ao valor da produção de leite (\%).

A metodologia quantitativa foi realizada com base no cálculo de custo de custo operacional efetivo conforme Matsunaga et al. (1976). Como os dados não compreendem análises anuais ajustes necessários para calcular o COT - Custo Operacional Total que inclui a depreciação, e o CT - Custo Total que inclui os juros sobre capital imobilizado não foram incluídos nessa análise, pois requerem análise de variação do inventário, bem como ajustes do custo da atividade leiteira e do leite que não poderiam ser realizados a contento com intervalo de apenas seis meses.

\section{Resultados e Discussão}

$\mathrm{Na}$ análise dos resultados levou-se em consideração características de curto prazo. Não foram consideradas características a longo prazo por não obter dados de um ciclo produtivo completo (um ano para a pecuária de leite). Todas as fazendas analisadas são propriedades familiares e forma denominadas de Fazenda A, B e C.

$\mathrm{Na}$ Tabela 1 são apresentados alguns dos indicadores referência da fazenda A selecionada. Na primeira fazenda analisada (Fazenda A), a área total (14 hectares) utilizada pela pecuária leiteira indica que o tamanho da propriedade é pequeno, sendo uma das características da atividade leiteira na região. Vale ressaltar que $65 \%$ da produção de leite no Brasil vem de pequenos produtores, considerando o estrato de produção de até 200L/dia (IBGE, 2006).

Tabela 1: Indicadores de tamanho, zootécnicos e econômicos de sistema de produção de leite no agreste pernambucano Fazenda A - estrato de produção até 200L/dia.

\begin{tabular}{l|c|c}
\hline Especificação & Unidade & Média \\
\hline Total de vacas (TV) & Animal & 9,00 \\
Vacas em lactação (VL) & Animal & 7,00 \\
Rebanho leiteiro total (RT) & Animal & 21,00
\end{tabular}


Área Total (A)

Produção Total (PT)

Produtividade $(\mathrm{P})$

Vacas em lactação/Total de vacas

Vacas em lactação/Rebanho leiteiro

Vacas em lactação/Área Total

Produção Total/Área Total

$\% \mathrm{COE} / \mathrm{RB}$

$\%$ Gasto com concentrado/ RB

\% Gasto com MDO Contratada/ RB

\begin{tabular}{c|c} 
ha & 14,00 \\
L/dia & 66,76 \\
L/vaca/dia & 9,50 \\
$\%$ & 77,80 \\
$\%$ & 32,90 \\
Animal/ha & 0,50 \\
L/ha/dia & 4,80 \\
$\%$ & 67,60 \\
$\%$ & 24,00 \\
$\%$ & 3,50
\end{tabular}

Em um rebanho bem estruturado, o número total de vacas e de aproximadamente $70 \%$, sendo $60 \%$ de vacas em lactação, $10 \%$ de vacas secas e $30 \%$ de bezerras e novilhas, com isso os animais que são destinados a manter o rebanho, são em menor número (ZOCCAL, 2014). Observa-se que o produtor obtém poucas vacas em relação ao rebanho, como também vacas em lactação, apresentando índices inferiores aos da pesquisadora supracitada, com $42,9 \%$ de vacas totais no rebanho, $54,4 \%$ de vacas em lactação e $15,6 \%$ de vacas secas no rebanho.

Os indicadores zootécnicos refletem diretamente nos meios de se atingir os resultados. O número de vacas em lactação/área utilizada na atividade leiteira incorpora medidas de eficiência reprodutiva como as de uso da terra. Já a produção total/área utilizada faz relação a quantidade de leite produzida por área utilizada, esses índices influenciam nos custos de produção e no lucro da atividade.

A produtividade animal é reflexo de vários fatores, principalmente a alimentação do rebanho, potencial genético para produção de leite e manejo utilizado no sistema. A produtividade média por vaca em lactação foi de $9,5 \mathrm{~L} / \mathrm{vaca} /$ dia. Neste quesito, a fazenda apresenta resultado superior a resultados encontrados em Minas Gerais 2005 que tiveram uma produção média de $6,09 \mathrm{~L} / \mathrm{vaca} /$ dia em propriedades incluídas no estrato de produção de 50 a 200 L/dia (GOMES, 2006).

A relação de vacas em lactação pelo total de vacas $(77,8 \%)$ é um indicador influenciado pela razão entre o período de lactação e o intervalo de partos. A redução da duração do intervalo de partos e/ou aumento do período de lactação acarreta em ampliação da relação VL/TV e consequentemente da proporção de VL no rebanho. Este indicador pode ser afetado pelo intervalo de partos e pelo período de lactação, além de sofrer influência da idade ao primeiro parto.

O número de vacas em lactação por área total utilizada na pecuária leiteria e a produtividade da terra são indicadores de intensificação do sistema de produção relacionados às tecnologias poupadoras do fator terra (GOMES, 2006). Os resultados destes indicadores 
para a Fazenda A foram 0,5 animal/ha e média de 4,8 L/ha/dia respectivamente. Em pesquisa realizada por Oliveira em 2007 para o estado da Bahia, o autor apresentou indicador de 0,42 unidade animal/ha menor que o apresentado na pesquisa.

Entre os indicadores clássicos utilizados como referência na avaliação de sistemas de produção de leite, está o gasto com concentrado para o rebanho em relação à renda bruta, gasto com mão-de-obra em relação à renda bruta e participação do custo operacional efetivo na renda bruta da atividade. As despesas com concentrado apresentou uma grande participação em relação ao valor da produção de leite. Este item representou uma média de $24 \%$, sendo próximo a resultados encontrados em sistemas com produção entre 50 e 200 litros/dia no estado de Minas Gerais de 24,61\% (GOMES, 2006).

Em relação mão de obra contratada, por se tratar de uma propriedade familiar, têm pouco ou nenhum gasto apresentando índice de 3,5\% em relação a renda bruta. Neste quesito, a produtividade é considerada também fator de intensificação, mas reflexo do uso de tecnologias mecânicas, poupadoras de mão-de-obra (GOMES, 2006).

O conhecimento das implicações do Custo Operacional Efetivo (COE) é fundamental na gestão do negócio, isto indica a viabilidade financeira a curto prazo. Quanto maiores forem esses valores, possivelmente menor será a taxa de remuneração do capital investido na atividade. A média da participação do custo operacional efetivo na receita bruta da atividade foi $67,6 \%$. Portanto constata-se que a renda bruta da atividade foi suficiente para cobrir os custos operacionais efetivos da propriedade.

Considerando os resultados encontrados para a Fazenda B (tabela 2), a área total utilizada foi de 20 hectares. Indicando também que o tamanho da propriedade é pequeno, porém maior que a fazenda A. Quanto a produção diária, a média apresentada foi de 204,82 L/dia, com máxima de $251 \mathrm{~L} /$ dia durante o período analisado, sabe-se que $18,8 \%$ da produção de leite no Brasil vem de produtores com estrato de produção de 200-500L/dia (IBGE, 2006).

Tabela 2: Indicadores de tamanho, zootécnicos e econômicos de sistema de produção de leite no agreste pernambucano Fazenda B- estrato de produção 200-500L/dia. Fonte: Dados da pesquisa (2015)

Especificação
Total de vacas (TV)
Vacas em lactação (VL)
Rebanho leiteiro total (RT)
Área Total (A)
Produção Total (PT)
Produtividade
Vacas em lactação/Total de vacas
Vacas em lactação/Rebanho leiteiro
Vacas em lactação/Área Total
Produção Total/Área Total
\% COE/ RB
\% Gasto com concentrado/ RB

\begin{tabular}{c|c} 
Unidade & Media \\
\hline Animal & 25,00 \\
Animal & 20,00 \\
Animal & 69,00 \\
ha & 20,00 \\
L/dia & 204,82 \\
L/vaca/dia & 10,70 \\
$\%$ & 78,48 \\
$\%$ & 29,77 \\
Animal/ha & 0,99 \\
L/há/dia & 10,24 \\
$\%$ & 66,11 \\
$\%$ & 27,79
\end{tabular}


O rebanho apresenta uma média de 69 animais e um total de 25 vacas e desse total 20 são vacas em lactação. Esses resultados indicam a necessidade de melhoria no sistema de produção, para atender o padrão ideal de um sistema bem estruturado, expostos por Zoocal (2014). Ao examinar a estrutura do rebanho, constata-se uma proporção de $78,48 \%$, embora o recomendado seja superior a $83 \%$ (GOMES, 2006). O reduzido número de vacas em lactação compromete a lucratividade da empresa, visto que são elas a principal fonte de renda.

A percentagem de vacas em lactação, em relação ao total rebanho foi de $29,7 \%$, o ideal para este indicador é de $60 \%$ com o valor mínimo de $40 \%$ (NETO, 2012). Este resultado está longe de ser ideal, pois quanto maior for o número de animais improdutivos no sistema, menor a representatividade de vacas leiteiras em relação ao rebanho total. Há necessidade de diminuir o número de animais improdutivos desta fazenda.

Considerados os fatores de intensificação relacionados com o uso da terra, a média encontrada foi de 0,99 animail, valor este considerado próximo ao ideal (uma vaca em lactação para cada hectare). Na análise da produção por área, foi encontrado uma média de 10,2 L/ha/dia, mesmo que não exista um valor considerado ideal, o valor encontrado representa um valor concensual de que uma maior produção por hectare está diretamente ligada a uma maior taxa de retorno sobre o capital investido (NETO, 2012).

$\mathrm{O}$ gasto com concentrado para o rebanho em relação à $\mathrm{RB}$, apresentou uma média de $27,8 \%$, sendo próximo ao valor considerado ideal (30\%). A participação do gasto com mãode-obra contratada em relação a RB apresentou média de 13,9\%. Estes indicadores de eficiência econômica são de grande importância ao se avaliar o equilíbrio econômico do sistema de produção, gastos excessivos com concentrado ou mão de obra reduzem as margens e compromete a sustentabilidade do exercício da atividade. A Fazenda B apresenta um COE de $66,1 \%$ sobre a RB, constata-se que a renda bruta da atividade foi suficiente para cobrir os custos operacionais efetivos da propriedade, no entanto a literatura recomenda $60 \%$ dos custos totais (GOMES; ALVES, 1999).

A tabela 3 apresenta os resultados da Fazenda C. Esta propriedade enquadra-se no estrato de produção acima de $500 \mathrm{~L}$ /dia, apresentando um volume de produção de 684,08 L/dia. Sabe-se que $16 \%$ da produção de leite no Brasil vêm de produtores com estrato de produção acima de 500L/dia (IBGE, 2006).

Tabela 3: Indicadores de tamanho, zootécnicos e econômicos de sistema de produção de leite no agreste pernambucano Fazenda C - estrato de produção acima de 500L/dia. Fonte: Dados da pesquisa (2015)

\begin{tabular}{l|c|c}
\hline Especificação & Unidade & Média \\
\hline Total de vacas (TV) & Animal & 47,00
\end{tabular}


Vacas em lactação (VL)

Rebanho leiteiro total (RT)

Área Total (A)

Produção Total (PT)

Produtividade

Vacas em lactação/Total de vacas

Vacas em lactação/Rebanho leiteiro

Vacas em lactação/Área Total

Produção Total/Área Total

$\% \mathrm{COE} / \mathrm{RB}$

$\%$ Gasto com concentrado/ RB

$\%$ Gasto com MDO Contratada/ RB

\begin{tabular}{c|c} 
Animal & 37,00 \\
Animal & 89,20 \\
ha & 57,00 \\
L/dia & 684,08 \\
L/vaca/dia & 18,50 \\
$\%$ & 79,23 \\
$\%$ & 40,66 \\
Animal/ha & 0,65 \\
L/há/dia & 12,00 \\
$\%$ & 66,48 \\
$\%$ & 38,80 \\
$\%$ & 31,70
\end{tabular}

O rebanho apresenta uma média de 89,2 animais e um total de 47 vacas, sendo 37 vacas em lactação. Esses resultados indicam a necessidade de melhoria no sistema de produção, uma sugestão é diminuir o número de vacas secas que representa percentual de $14,9 \%$, e também o número de animais improdutivos (novilhas e bezerros) que apresentam em média 47,3 \% do rebanho total. A produtividade média por vaca em lactação foi de 18,5 L/vaca/dia índice considerado elevado em comparação a resultados encontrados em Minas Gerais 2005 , a produção média foi de $10,48 \mathrm{~L} / \mathrm{vaca} /$ dia para produtores incluídos no estrato de produção de 500-1000 L/dia.

A percentagem de vacas em lactação, em relação ao total rebanho foi de $42 \%$. Segundo Camilo Neto et al. (2012) o ideal para este indicador é de $60 \%$ com o valor mínimo de $40 \%$. Este resultado está entre o valor mínimo estabelecido e a média do indicador ideal. Sugere-se diminuir o número de animais improdutivos no sistema produtivo desta fazenda, a fim de tornar-se mais eficiente e ter mais vacas em produção.

Considerados os fatores de intensificação relacionados com o uso da terra a média encontrada foi de 0,65 animail, valor este considerado baixo em relação ao ideal (uma vaca em lactação para cada hectare). Já as despesas com concentrado apresentou uma grande participação em relação ao valor da produção de leite, esse item representou uma média de $38,8 \%$. Sendo superior ao valor considerado ideal (30\%) e superior a valores encontrados por Camilo Neto et al. (2012).

A participação do gasto com mão-de-obra contratada em relação a RB apresentou média de $31,7 \%$, índice considerado alto em relação ao ideal (20\%). Apresenta COE 66,48 \% sobre a Renda Bruta. Constatou-se que a renda bruta da atividade foi suficiente para cobrir os custos operacionais efetivos da propriedade. As despesas com concentrado apresentou uma grande participação em relação ao valor da produção de leite, com índice de 38,8\%, superior ao índice considerado ideal que é de $30 \%$. 
Partindo para uma análise comparativa entre as fazenadas A, B e C. Não se pode avaliar somente a parte econômica da atividade leiteira, sem avaliar, paralelamente, como estão os índices do rebanho. Uma ineficiência técnica pode comprometer a atividade leiteira, elevando os custos de produção e reduzindo a lucratividade. Pois muitas vezes o insucesso da atividade está relacionado aos índices zootécnicos da propriedade que não estão dentro dos ideais. No quesito volume de produção a fazenda $\mathrm{C}$ apresentou o maior nivel de produção (684,08L/dia), seguidas pelas fazendas B (204,82 L/dia) e A (66,76 L/dia) respectivamente. Estes indicadores são muito importantes por exercer grande influência sobre o comportamento dos custos de produção e no lucro da atividade.

Para o indice produtividade foi encontrado uma média de 9,50 litros/vaca em lactação/dia para a fazenda A, 10,70 para fazenda B e, 18,50 para a fazenda C. Já a produtividade representa a quantidade de litros de leite produzido por vaca/dia, em lactação. A obtenção de maiores níveis de produtividade é condição para um desempenho econômico eficiente. Uma das alternativas para o aumento da produtividade e a melhoria do padrão genetico do rebanho e a alimentação.

\section{Conclusões}

Os produtores familiares procuram obter o melhor resultado possível de suas atividades. Para isso, uma das condições necessárias é a gestão adequada dos custos. A caracterização dos sistemas de produção de leite traz vários esclarecimentos sobre a viabilidade econômica dos diferentes sistemas de produção. Neste quesito procurou-se analisar os fatores, que além de condicionar a produção de leite, são considerados no processo de caracterização das unidades produtoras.

Estas informações são relevantes à medida que permitem a identificação de fatores limitantes à evolução do processo produtivo, levando-se em conta os contrastes e peculiaridades observados entre os estratos de produção. Neste sentido, traçou-se o perfil da produção nas fazendas considerando-se o nível de produção, a produtividade média por vaca em lactação e os resultados econômicos das propriedades observadas.

A indentificação dos melhores processos de produção, permite uma gestão mais eficaz da propriedade e fornece indicadores de referencias para propriedades cujas características são semelhantes às fazendas observadas, considerando os critérios de comparação estabelecidos. O intercâmbio das informações tecnológicas e de gestão favorece a definição de estratégias de gestão mais aplicada para as unidades produtoras. 
Portanto, os indicadores de Benchmark resultantes para a medição de desempenho mostraram-se muito eficaz. De forma a verificar a viabilidade operacional e econômica da atividade de produção leiteira no agreste pernambucano. Fornecendo acurácia de informações indispensáveis para o planejamento e tomada de decisão dos produtores rurais em vista do desenvolvimento do setor leiteiro na microrregião de Garanhuns.

\section{Referências}

CAMILO NETO, M. et al. Identification and quantification of benchmarks of milk production systems in Minas Gerais. Revista Brasileira de Zootecnia, v. 41, n. December 2006, p. 2279-2288, 2012.

FASSIO, L. H. et al. Custos e Shut-Down Point da atividade leiteira em Minas Gerais. Revista de Estudos Regionais, v. 43, n. 4, p. 759-777, dez. 2005.

GOMES, A. P.; ALVES, E. I. Identificando ineficiências na produção de leitePiracicabaBoletim do leite, , 1999.

GOMES, S. T. Benchmark da produção de leite em MG. Departamento de Economia Rural - UFV, n. 182, p. 1-4, 2005.

GOMES, S. T. Diagnóstico da Pecúaria Leiteira so estado de Minas Gerais em 2005Relatório de pesquisa. Belo Horizonte: [s.n.].

IBGE - INSTITUTO BRASILEIRO DE GEOGRAFIA E ESTATÍSTICA. Censo Agropecuário. Disponível em: <www.sidra.ibge.gov.br/bda/tabela/listabl.asp?c=281\&z=p\&o=2\&i=P>. Acesso em: 6 maio. 2016.

IBGE - INSTITUTO BRASILEIRO DE GEOGRAFIA E ESTAtÍSTICA. Pesquisa Pecuária Municipal 2014. Disponível em: <http://www.sidra.ibge.gov.br/bda/pesquisas/ppm/default.asp>. Acesso em: 20 abr. 2016.

JANK, M. S.; FARINA, E. M.; GALAN, V. B. O Agribusiness do leite no Brasil. $1^{\circ}$. ed. São Paulo: Milkbizz, 1999.

KRUG, E. E. B. Estudo para identificação de Benchmarking em sistemas de produção de leite no Rio Grande do Sul. Porto Alegre: Universidade Federal do Rio Grande do Sul, 2001.

LOPES, M. A. et al. Efeito do tipo de sistema de criação nos resultados econômicos de sistemas de produção de leite na região de Lavras (MG) nos anos de 2004 e 2005. Ciência Animal Brasileira, v. 8, n. 3, p. 359-371, 2007.

LOPES, M. A.; CARVALHO, F. M. Custo de produção do leite: Boletim agropecuário 32.LavrasUFLA, , 2000.

MARION, J. C.; SANTOS, G. J. DOS; SONIA, S. Administração de Custos na Agropecuária. 4. ed. São Paulo: Atlas, 2009.

MATSUNAGA, M. et al. Metodologia de custo de produção utilizada pelo IEA. Agricultura em São Paulo Boletin Técnico do Instituto de Economia Agrícola, v. 23, n. 1, p. 17, 29 mar. 1976.

MENEGAZ, E. et al. Análise dos coeficientes de desempenho técnico e econômico que 
caracterizam as Unidades Produtoras benchmark na atividade leiteira no RS. ConTexto, v. 6, n. 9, p. 1-23, 2006.

OLIVEIRA, A. S. DE et al. Identificação e quantificação de indicadores-referência de sistemas de produção de leite. Revista Brasileira De Zootecnia, v. 36, p. 507-516, 2007.

REIS FILHO, R. J. C. DOS; SILVA, R. G. DA. Cenários para o leite e derivados na Região Nordeste em 2020. Recife- PE: SEBRAE, 2013.

REIS, R. . Fundamentos de economia aplicadaLavrasUFLA/FAEPE, , 2002.

TUPY, O.; YAMAGUCHI, L. C. T. Identificando Benchmarks na produção de leite. Revista de Economia e Sociologia Rural, v. 40, n. 1, p. 81-96, 2002.

ZOCCAL, R. Conjuntura do leite no primeiro semestre. Revista Balde Branco, p. 70, 2014. 